\title{
Evaluation of Natural ventilation on temperature and pressure distribution in a road Tunnel fire with vertical shaft
}

\author{
I. Benabdelaziz, M.Bouterra, Afif El Cafsi, A. Belghith \\ LETTM, Faculté Sciences de Tunis Campus Universitaire 1060 Tunis, TUNISIE \\ E-mail address: benabdellazizimen@gmail.com; mourad.bouterra@gmail.com
}

Keywords: Natural Ventilation; plug-holing; FDS; Tunnel

\begin{abstract}
This paper has analysed the influence of plug-holing on thermal and pressure field evolution in urban road tunnel fires with vertical shaft by Large Eddy Simulation (LES). Results show that the temperature reduction rate is about $70 \%$ at the tunnel half and it increases about $80 \%$ at the ceiling level. The pressure field is characterized by a pseudo-periodic behavior which reaches a maximum reduction rate $(78 \%)$ in case of natural ventilation. The numerical tool used is FDS (version 5).
\end{abstract}

\section{Nomenclature :}

Densité

P Pression

T Température

Différence de la température

Tenseur de contrainte

F Force volumique

Pr Nombre de Prandtl
Sc Nombre de Schmidt

CS Nombre de Smagorinsky

L Longueur du tunnel

1 Largeur du tunnel

Chaleur spécifique

Conductivité

Diffusivité turbulente

\section{INTRODUCTION}

The morphology of a natural ventilation system consists essentially of a resultant action of forces of nature that refers to the intentional movement of air caused by the static pressure of wind or a temperature difference between the inside and outside. This type of ventilation is relevant to many area to feature buildings, atrium, as well as fires in road tunnels [1]. The latter is sometimes very strong component of the problem. This is to evacuate the fumes to the outside by natural thermal draft. In the case of reinforcing a quantity of air beneath the layers of this pollutant to driving, a mixture is established between the two species that will cause extraction of non considered species. This exhaustion directly or indirectly is called "chimney effect".

This type of ventilation has been widely developed. Experimentally CG Fan et al [2] analyzed the air training model in a vertical pipe through chimney effect. The evolution of the temperature increase that has measured by the height is almost identical to our numerical result. W.Zhong et al [3] have studied numerically the influence of the longitudinal wind speed in a road tunnel by the FDS code. They claimed that the plug-Holling occurs with lower value. Through a combination of this type of ventilation and that of a longitudinal ventilation, Brahim Kalech et al [4] studied the effect of these two ventilation systems on the temperature distribution using the CFD code ( SDS).

The objective of this work is to numerically study the subject FDS code [5,6] the thermal field and pressure field based on 2 cases of simulation (in the presence and absence of natural ventilation). 


\section{GEOMETRY AND BOUNDARY CONDITIONS}

2 geometries used are as follows:
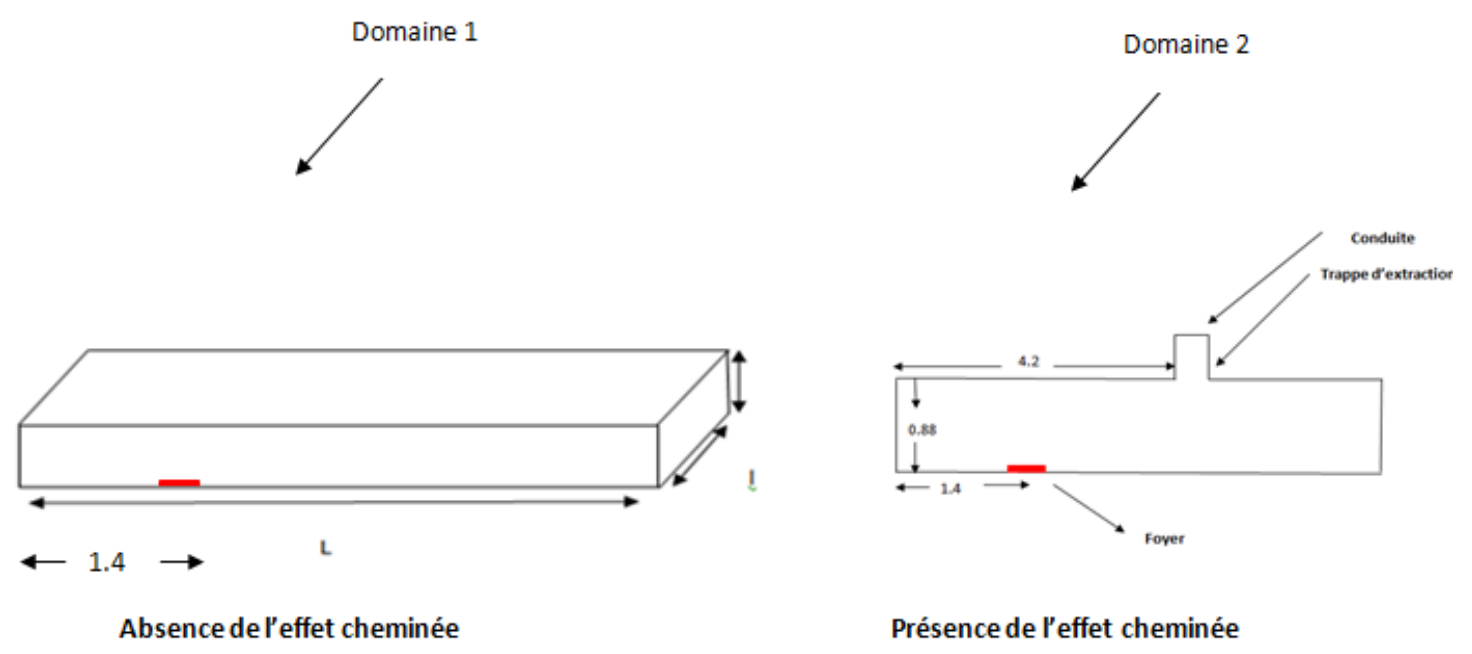

Figure 1 : Configurations Géométriques et conditions aux limites

In order to set up the configuration, perform the boundary conditions to lead to an easier presentation that helps us understand the study and more. The estate consists of a rectangular section of length $\mathrm{L}(6 \mathrm{~m})$ of width $(2 \mathrm{~m})$ and equal to $0.88 \mathrm{~m}$ height. The thermal source is placed A1.4 $\mathrm{m}$ of the left input of the two fields used to generate a plume (through the N-heptane fuel) of rectangular cross section and size $(20 * 15) \mathrm{cm}$.

Driving the field 2 is arranged vertically height $0.8 \mathrm{~m}$, a rectangular section and size $(30 * 30) \mathrm{cm}$ located at $4.2 \mathrm{~m}$ from the left input. Input sections, discharge and the upper part of the pipe are subjected to the "OPEN" structure of SDS.

\section{DIGITAL MODEL:}

FDS (Fire Dynamics Simulator) developed by NIST (the National Institute of Standards and Technology) in 2006 to study the behavior of fires. Under the hydrodynamic model, the conservation equations are described as follows:

\section{Conservation de la masse :}

$$
+\quad)=0
$$

-Conservation de la quantité de mouvement :

$$
-\quad)+
$$

-Conservation de l'énergie : 
In this study, we will use the method of LES (Large Eddy Simulation) pathway is icts Ability to model the turbulence.

The model Smagorinsky defined as:

$$
=\quad ; \quad=1 / 2 \leftarrow \quad+
$$

It also defines three dimensionless numbers located successively in the way follows: The Prandtl number (Pr), the Schmidt number (Sc) and the number Smagorinsky (Cs).

These constant 3 taken successively in this study as: $0.5,0.5$ and 0.2 .

\section{INFLUENCE OF THE CHIMNEY EFFECT ON THE DISTRIBUTION OF THE HEAT FIELD AND THE PRESSURE FIELD:}

We will study the spatial and temporal distribution of temperature and pressure for different regions of the tunnel based on 2 cases of simulation.

\subsection{Influence of the chimney effect on the distribution of thermal field:}

Case 1: No chimney effect:

The spatial variation of the increase in the latter measured at the right opening of the tunnel is illustrated in Figure 2 for this case. It is noticed that the curve is composed of 3 parts. The first part is represented by a horizontal line corresponds to scales to $0.65 \mathrm{~m}$. Beyond this height increases to $0.85 \mathrm{~m}$ (with a maximum value obtained of about $100 \mathrm{~K}$ ), following a weak back down corresponds to a value of $88 \mathrm{~K}$.

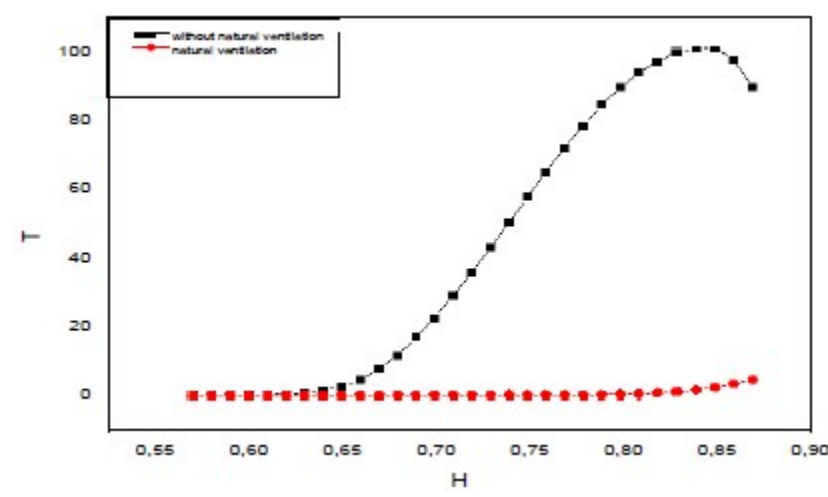

Figure 2. Temperature increase measured at the ceiling and under the conduct in the absence and presence of the effect

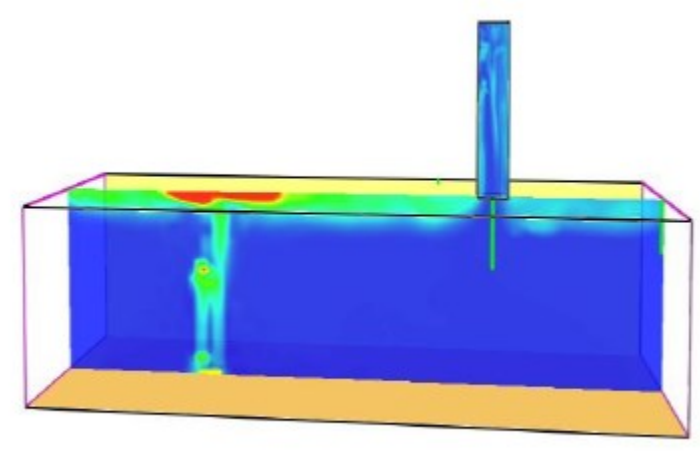

Figure 3. Schematic illustration of the process of the chimney effect

The temporal evolution of the temperature for 4 different regions of the tunnel is organized according to the histograms placed on it (Figure 4). This is a temporal continuity according to the environmental conditions $(0.56 \mathrm{~m}$ and $0.63 \mathrm{~m}$ respectively), about $80 \mathrm{~K}$ to half of the tunnel and $170 \mathrm{~K}$ at ceiling level that is due to the smoke layer which is very thick and will avoid such penetration of the other species through the pores. The accumulation of pollutant in the top of the tunnel with a very high heat will result in an increase in the level of this field. 


\section{Case 2: Presence of the chimney effect:}

In the presence of the vertical pipe, Figure 2 shows a very severe reduction in the temperature gradient approaches $0 \mathrm{~K}$. This tells us there to a perfect appearance of a process caused by the disposal of the latter and will inducing reduction. For this we will follow the temporal evolution of the temperature as in the other cases. It is very clear that this value does not exceed $25 \mathrm{~K}$ for the 4 positions (Figure 5). This situation can be explained by penetration of quantities of air directly into the pipe through the hatch which is located between the driving-ceiling background, or a building is established under the layers of smoke which encourages mixing between 2 species until such a time the layer of fresh air is thickened relative to the other layer ultimately leading to a training of this kind throughout the flight to conduct. This is called "chimney effect", as is well shown in Figure 3.

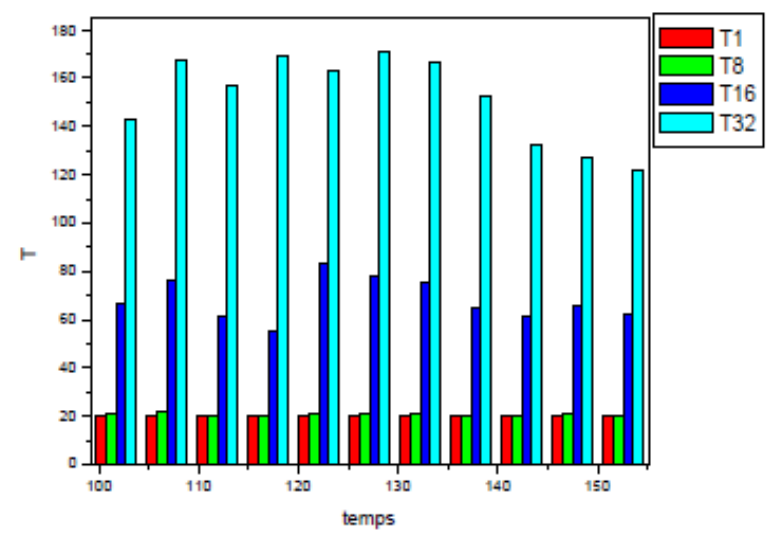

Figure 4. Temperature variation versus time (absence of the chimney effect).

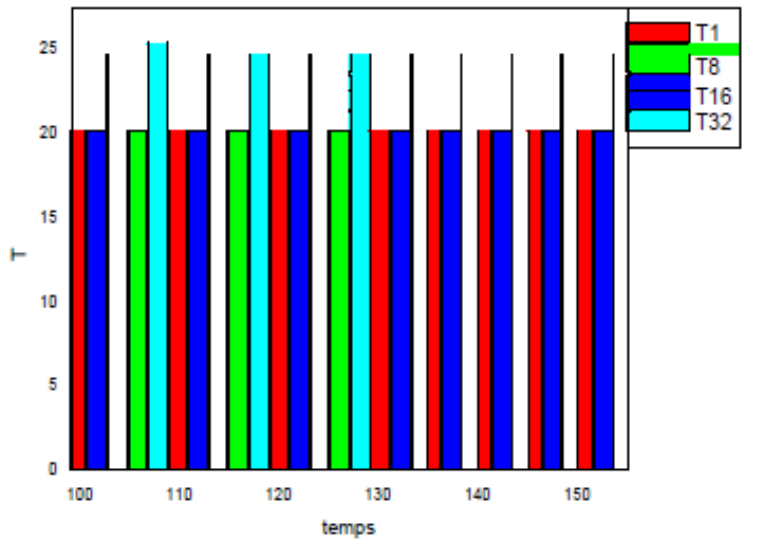

Figure 5. Variation of the temperature in function of time (the presence of the chimney effect).

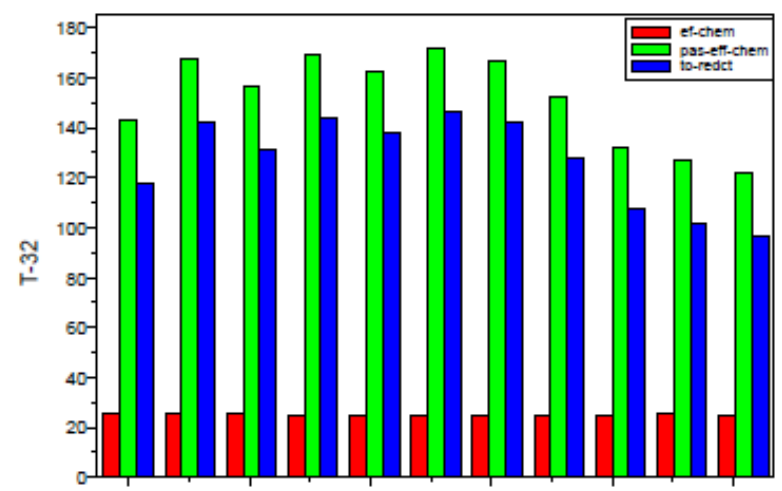

Figure 6. The temperature change with time (presence and absence of the chimney effect) + reduction.

Then it can be concluded that in the case without natural ventilation, the upper portion (the highest position of the thermocouple) is within the smoke layer; whereas the lower portion corresponds to, is inside of the layer of fresh air. However, in the case of natural ventilation, the behavior of this gradient approaches $0 \mathrm{~K}$, illustrates that the measurement position is located in the air layer such that the stack effect occurs.

It may be noted also based on these measured values, the temperature reduction rate is about $70 \%$ to half of the tunnel, against it increases by $80 \%$ at the ceiling as the difference between the two simulated cases (Figure 6). 


\section{4-2 Influence of the chimney-effect on the distribution of the pressure field:}

\section{Case 1: No chimney effect:}

This assessment results in a pseudoperiodic behavior in these profiles. The slowdown that characterizes this type of periodicity is effected by the presence of peaks in the center of each pseudo-period that gradually decreases from the first time interval until the fourth. One can easily estimate that the maximum value mitigated by the peak pressure is $0.28 \mathrm{~Pa}$. Beyond this interval of time, the peak can divide into 2 periods while heading weakly negative values. It necessarily is a natural pressure difference of air movement from the tunnel portals 2 (Figure 7).

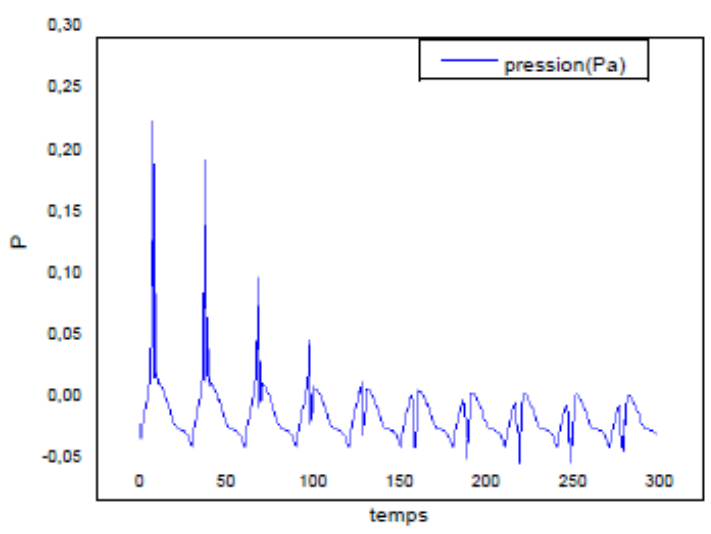

Figure 7. Time evolution of the pressure field in the tunnel case absence of the chimney effect

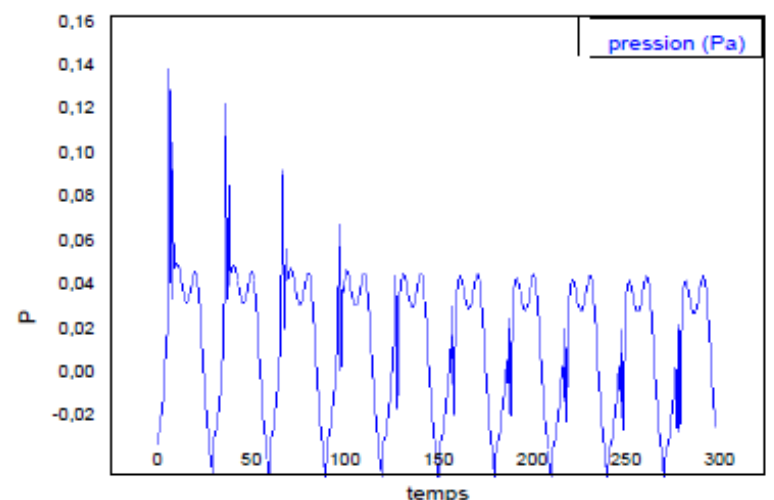

Figure 8: Time evolution of the pressure field in the tunnel case Presence of the chimney effect.

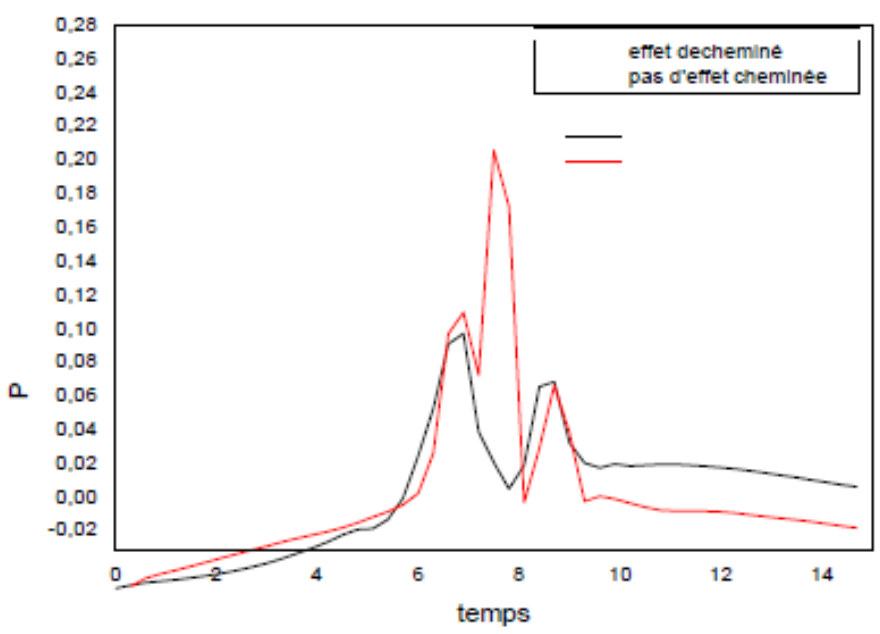

Figure 9: Pressure fields in a specific interval. ( 2 cases)

\section{Case 2 : Présence de l'effet de cheminée :}

Case 2: Presence of the chimney effect:

In the presence of this process, a very remarkable reduction occurs at the maximum peak of the pressure field will be $(0.15 \mathrm{~Pa})$. In this case, all these pseudo frequencies are divided into 2 and the peak takes the position at the beginning of the first division instead of the center covered by each of them as is well marked as in figure 8. It is estimated that these pseudo-periodicities are strengthened in the negative $(-0.02 \mathrm{~Pa})$. This is probably an adverse pressure gradient illustrating the direction against rotation between the two species indicating the Air Training able to conduct then will the seat of production of the plug-holing. 
It may be noted as well as the slowdown that is established in the pressure field to the negative value is the key parameter for the appearance of the plug-Holling effect. Indeed, in case of mixing between the cold air and the hot smoke, a disturbance takes place over the air-interface smoke which in turn results in a significant increase in flow resistance which will generate a gradient adverse pressure until the arrival of a certain time that the system becomes unable to overcome the pressure gradient. At this time, fresh air from the outside will spread in the line very easily.

Yet it can be estimated by means of Table 1, the rate of reduction of pressure between the case 2 to 3 minutes is about $70 \%$ as an average value.

Table 1. Pressure field reduction rate for two simulated cases.

\begin{tabular}{clll}
\hline Temps(s) & $\begin{array}{c}\text { Absence de l'effet } \\
\text { cheminé }\end{array}$ & $\begin{array}{c}\text { Présence de l'effet } \\
\text { cheminée }\end{array}$ & Taux de réduction \\
\hline $\mathbf{3 0 0}$ & 0.00451 & 0.00154 & $65 \%$ \\
$\mathbf{2 0 0}$ & 0.05849 & 0.01429 & $75 \%$ \\
$\mathbf{1 0 0}$ & 0.05958 & 0.02088 & $64 \%$ \\
\hline
\end{tabular}

Both Figure 9 provides information on the particular appearance of the belly lack of natural ventilation as indicated by the peak pressure $(0.28 \mathrm{~Pa})$ in the fourth interval of time. In the presence of the vertical pipe, stomach turns at a pressure trough with a value of $0.06 \mathrm{~Pa}$. Subsequently, the reduction rate reached $78 \%$, which represents the maximum rate reduced through the onset of the effect of thermal draft.

Finally, one can conclude that natural ventilation is due to two effects, each of which may have more or less important depending on the case: The drawing that appears in that there are differences in temperature and movement of traffic air which creates pressure on certain faces and depressions on others.

\section{CONCLUSION}

In this work, we have studied the process of the chimney effect in a road tunnel with a vertical pipe based on the temperature field and the pressure field.

The results show that:

- The perfect reduction at the distribution of temperature and pressure established, will host the occurrence of this phenomenon.

- It was confirmed that the effect plug-holing inside the pipe leads to a large mixing effect between the layer of hot smoke and cold fresh air. For this, an amount of air in the pipe will be strengthened considerably. The results are in good agreement with previous work.

\section{References}

[1] L.H.Hu et al (2010), Longitudinal distribution of CO concentration and difference with temperature field in a tunnel fire smoke flow, International Journal of Heat and Mass Transfer, pp 2844-2855.

[2] C.G.Fan et al (2013), Expeimental Study of air entrainment mode with natural ventilation using shafts in road tunnel fires, International Journal of Heat and Mass Transfer, pp 750-757.

[3] W.Zhong et al (2013), Influence of longitudinal wind on natural ventilation with vertical shaft in a road tunnel fire, , International Journal of Heat and Mass Transfer, pp 671,678. 
[4] Kalech Brahim, Bouterra Mouad,El Cafsi Afif,Belghith Ali (2011): Study of the temperature Distribution in a Road tunnel under the Effect of two ventilation Systems, Scientific Research,pp231-242.

[5] Kevin Mc Grattan, Randall Mc Dermott, Simo Hostikka, Jason Floyd (2010), Fire Dynamics Simulator (version 5) User's Guide, NIST Special Publication 1019-5,June 23, 2010.

[6] Kevin Mc Grattan, Simo Hostikka, Jason Floyd, Howard Baum, Ronald Rehm, William Mell, Randall Mc Dermott (2010), Fire Dynamics Simulator (version 5) Technical Reference Guide, NITS Special Publication 1019-5,June 23,2010. 